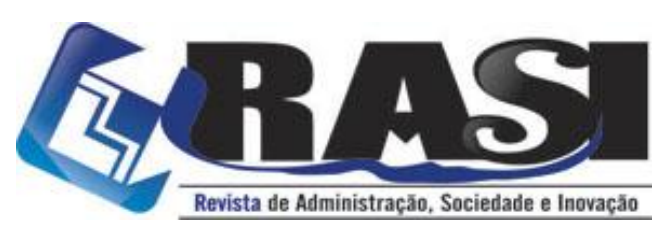

http://www.rasi.vr.uff.br

RASI, Volta Redonda/RJ, v. 7, n. 3, pp. 47-68, Set./Dez. 2021

\title{
Educação Empreendedora nos Cursos de Graduação da Universidade Federal da Grande Dourados (UFGD)
}

\author{
Rui Ernesto Ribas Zanchet (UFGD) - ruizanchet@gmail.com \\ Luan Carlos Santos Silva (UFGD) - luancarlos@ufgd.edu.br
}

\begin{abstract}
Resumo:
Este estudo tem como objetivo analisar o processo de institucionalização da educação voltada ao empreendedorismo na Universidade Federal da Grande Dourados (UFGD). Foram identificados projetos de ensino, pesquisa e extensão que promovem esta forma de educação e compreender como o tema é percebido pelos coordenadores de cursos de graduação do universo selecionado. Para clarificar conceitos como educação por competências, competências empreendedoras e empreendedorismo utilizou-se obras de autores, nacionais e estrangeiros, que se dedicam amplamente ao estudo do tema. Foi adotada uma abordagem mista, qualitativa empregada em entrevistas e quantitativa para mensuração de dados. Observou-se que a maioria dos entrevistados acreditam que esta forma de educação é importante para o acadêmico, principalmente para coordenadores de cursos de graduação na modalidade de bacharelado. Existe a necessidade de aprimoramento dos métodos e formas de implementação da educação empreendedora, sobretudo com a criação de um ambiente favorável a práticas empreendedoras tanto para docentes quanto discentes. O resultado apresentado procura fornecer subsídios para a criação de políticas públicas dentro UFGD e, sendo possível, em outras universidades visando fomentar a educação empreendedora na formação profissional. Este estudo contribui para o aprimoramento da educação empreendedora na UFGD visto que foram achados indícios de que ainda é pouco desenvolvida, possuindo espaço para crescimento.Há dificuldade de generalização pois se trata de um estudo de caso único e pontual.
\end{abstract}

Palavras-Chave: Empreendedorismo; Educação Empreendedora; Competências Empreendedoras; Formação Profissional.

\section{Entrepreneurial Education in Graduation Courses of Universidade Federal da Grande Dourados (UFGD)}

\begin{abstract}
:
This study aims to analyze the institutionalization process of education focused on entrepreneurship at the Federal University of Grande Dourados (UFGD). Teaching, research and extension projects were found that promote this form of education and understand how the theme is perceived by the coordinators of undergraduate courses in the selected universe. In order to clarify concepts such as competency education, entrepreneurial skills and entrepreneurship, works by authors, both national and foreign, were used that are largely dedicated to the study of the theme. A mixed, qualitative approach employed in interviews and a quantitative approach to data measurement was adopted. It was observed that the majority of respondents believe that this form of education is important for the academic, especially for coordinators of undergraduate courses in the bachelor's degree. There is a need to improve the methods and ways of implementing entrepreneurial education, especially with the creation of an environment favorable to entrepreneurial practices for both teachers and students. The presented result seeks to provide subsidies for the creation of public policies within UFGD and, if possible, in other universities aiming at promoting entrepreneurial education in professional training. This study seeks to contribute to the improvement of entrepreneurial education at UFGD since there were signs that it is still underdeveloped, with room for growth. It is difficult to generalize because it is a unique and specific case study. Keywords: Entrepreneurship; Entrepreneurial Education; Entrepreneurial Skills; Professional Qualification.
\end{abstract}

\begin{tabular}{c} 
R. Desembargador Ell Universidade \\
$27213-415$ - Volta Redonda, RJ - Brasil \\
www.uff.br \\
\hline $\begin{array}{c}\text { Federal } \\
\text { Fluminense }\end{array}$ \\
$\begin{array}{c}\text { Copyright (C) 2020 RASI. Todos os direitos, até mesmo de tradução, são reservados. É } \\
\text { permitido citar parte de artigos sem autorização prévia, desde que seja identificada a fonte. }\end{array}$ \\
\hline
\end{tabular}




\section{Educação Empreendedora nos Cursos de Graduação da Universidade Federal da Grande Dourados (UFGD)}

\section{Introdução}

O presente artigo procura demonstrar a importância da educação empreendedora e o papel desempenhado pela UFGD na disseminação dessa modalidade de ensino, está divido em quatro partes principais, sendo elas: a) Referencial Teórico-normativo onde são abordados assuntos como educação por competências, política educacional no Brasil e educação empreendedora nos cursos da UFGD; b) Procedimentos Metodológicos; c) Análise dos Resultados e; d) Considerações Finais.

O volume de artigos sobre empreendedorismo cresceu em números nos últimos anos e segundo a visão de alguns pesquisadores como Drucker (1987), Filion (1999), Etzkowitz e Leydesdorff (1995), Dolabela (2011) e Dornelas (2018), representa um elemento indutor do desenvolvimento econômico e social, repercutindo em diversas áreas do conhecimento. A universidade desempenha um papel preponderante na formação de profissionais aptos para explorar as oportunidades além de aproveitar social e economicamente o conhecimento científico produzido (Etzkowitz \& Leydesdorff, 1995, 2000; Salomão, 2014; Santos, 2017; Dornelas, 2017, 2018).

Esta forma de educação surgiu em meados do século XX, na Harvard Business School, sob a denominação de 'gerenciamento de pequenas empresas'. Foi a partir da década de 1980, que o tema teve destaque no campo educacional nos Estados Unidos, Canadá e França com pesquisas nas áreas das ciências humanas e sociais aplicadas. Inicialmente, os estudos buscavam solucionar problemas relativos à mortalidade de novos empreendimentos e tentavam articular o relacionamento entre universidades e empresas (Drucker, 1987; Filion, 1999; Coan, 2011; Santos, 2017).

Diversos pesquisadores defendem que o perfil empreendedor pode ser despertado/incentivado por meio da educação (Pereira, 2001; Fenando, 2011; Dornelas, 2018; Dolabela \& Filion, 2013; Drucker, 1987; Filion, 1999). Percebendo a importância do tema, principalmente para as universidades, o objeto deste artigo é a educação voltada para o empreendedorismo nos cursos de graduação da Universidade Federal da Grande Dourados UFGD.

A educação empreendedora não deve ser vista como uma resposta milagrosa a solução de problemas estruturais de um país, mas sim como a oportunidade de melhoria das capacidades do indivíduo e de grupos de indivíduos em suas habilidades empreendedoras. Esta forma educacional deve estar voltada ao estimulo à iniciativa, ao diagnóstico crítico e a cooperação e assessorar o poder público implantar políticas públicas capazes de oportunizar ambiente favorável ao empreendedorismo (Albuquerque et al., 2016; Santos \& Alvarenga, 2019).

A educação empreendedora emergiu das novas necessidades impostas pelo mercado de trabalho contemporâneo. A reestruturação dos fatores de produção faz com que cada vez menos se utiliza mão-de-obra devido aos fatores científico-tecnológicos. Esses fatores exigem dos novos profissionais maior criatividade, adaptabilidade e proatividade (Albuquerque et al., 2016; Amaro \& Brunstein, 2013; Oliveira et al., 2016; Santos \& Alvarenga, 2019).

A presente pesquisa tem como objetivo geral avaliar o processo de institucionalização da educação voltada para o empreendedorismo na UFGD. Para alcançar o objetivo geral buscou-se investigar políticas públicas governamentais e setores de direção e/ou coordenação 
ligados à Reitoria que porventura influenciem diretamente na tomada de decisão de implantar ou não disciplinas voltadas ao empreendedorismo nos cursos de graduação da universidade.

Para atingir o objetivo geral foram listados os seguintes objetivos específicos: I) Identificar junto as Pró-reitorias os projetos de ensino, pesquisa, pós-graduação e extensão com foco no empreendedorismo; II) Compreender como o ensino do empreendedorismo é percebido pelos coordenadores de cursos de graduação; III) Mapear as principais políticas públicas de ensino do empreendedorismo do Governo Federal.

Também foram arguidas algumas questões-problema: I) Existe uma política institucional voltada ao ensino do empreendedorismo na UFGD?; II) Como o tema é compreendido e ensinado nos cursos de graduação da UFGD?; III) Existe uma agenda de pesquisa e extensão de ensino voltado ao empreendedorismo na UFGD?; IV) Quais metodologias são utilizadas pelos gestores da UFGD para implantar, estimular e intensificar uma educação voltada para o empreendedorismo?

\section{Referencial Teórico-Normativo}

\subsection{Educação por Competências}

A adequação do ensino a nova realidade social é objeto de discussão a nível nacional e internacional, iniciando-se nos Estados Unidos a partir da década de 1960, quando se observou o distanciamento entre o ensino acadêmico e a realidade social e laboral da população. McClelland em 1973 intensificou o debate sobre a educação por competência propondo que se investigasse fatores de sucesso de pessoas que tiveram desempenho profissional superior às demais e a partir disto determinar quais destes fatores poderiam ser ensinados. Aos elementos de êxito McClelland chamou 'competências' (Fleury \& Fleury, 2001; McClelland, 1973).

A partir dos estudos de McClelland (1973), outros pesquisadores dedicaram-se ao tema 'educação por competências', cada um buscando uma definição que melhor atendesse as necessidades da sociedade em determinado tempo. O Quadro 1 procura sintetizar a evolução no tempo das principais definições de competências.

\section{Quadro 1. Definições de Competências}

\begin{tabular}{|c|l|}
\hline Autor & \multicolumn{1}{c|}{ Definição de Competência } \\
\hline $\begin{array}{c}\text { McClelland } \\
(1973)\end{array}$ & $\begin{array}{l}\text { Competência é uma característica implícita a uma pessoa relacionada com capacidade de } \\
\text { realização de determinada tarefa de maneira superior a de outras. }\end{array}$ \\
\hline Le Boterf (1995) & $\begin{array}{l}\text { Competência é a sinergia de uma pessoa com sua formação educacional e sua experiência } \\
\text { profissional. É o agir com responsabilidade mobilizando, integrando e transferindo } \\
\text { conhecimentos, recursos e habilidades num determinado ambiente de trabalho. }\end{array}$ \\
\hline Zarifian (1999) & $\begin{array}{l}\text { Competência é uma inteligência prática das situações que se apoiam sobre os conhecimentos } \\
\text { adquiridos e os transformam, com tanto mais força quanto a diversidade das situações } \\
\text { aumentam. } \\
\text { Competência é a faculdade de mobilizar os recursos dos atores em torna das mesmas situações, } \\
\text { para compartilhar os acontecimentos, para assumir os domínios de corresponsabilidade. }\end{array}$ \\
\hline Perrenoud & $\begin{array}{l}\text { Competência é a aptidão para enfrentar uma família de situações análogas, mobilizando de } \\
\text { forma correta, rápida, pertinente e criativa, múltiplos recursos cognitivos: saberes, capacidades, } \\
\text { micro-competências, informações, valores, atitudes, esquemas de percepção, de avaliação e de } \\
\text { raciocínio. }\end{array}$ \\
\hline Ramos (2006) & $\begin{array}{l}\text { A competência deve ser conformada pelos conhecimentos, habilidades, destrezas, compreensão } \\
\text { de atitudes, que podem ser identificadas na etapa de investigação das competências } \\
\text { profissionais para o desempenho competente em uma determinada função produtiva. }\end{array}$ \\
\hline BNCC (2020) & $\begin{array}{l}\text { Competência é definida como a mobilização de conhecimentos (conceitos e procedimentos), } \\
\text { habilidades (práticas, cognitivas e socioemocionais), atitudes e valores para resolver demandas } \\
\text { complexas da vida cotidiana, do pleno exercício da cidadania e do mundo do trabalho. }\end{array}$ \\
\hline
\end{tabular}

Fonte: elaborado pelo autor. 
A partir da década de 1980, nos Estados Unidos, percebeu-se a necessidade em formar profissionais capazes de acompanhar as rápidas mudanças do mercado de trabalho, aproximando a teoria da prática. No Brasil essa mudança ocorreu a partir da Lei de Diretrizes e Bases da Educação (LDB), Lei no 9.394/1996, que concedeu às universidades públicas autonomia didático-científica e financeira, permitindo à própria universidade modificar sua estrutura curricular (Siqueira \& Nunes, 2011; McClelland, 1973; Brasil, 1996).

Outra norma de grande importância que procura fomentar a implementação de uma educação por competências é a Base Nacional Comum Curricular (BNCC), contudo é importante destacar que se trata de uma diretriz voltada ao ensino infantil, fundamental e médio. A BNCC é "um documento de caráter normativo que define o conjunto orgânico e progressivo de aprendizagens essenciais que todos os alunos devem desenvolver ao longo das etapas e modalidades da Educação Básica" (Brasil, BNCC, 2020, p. 7).

Este modelo procura desenvolver no aluno capacidades de resolução de problemas concretos, compreensão de conhecimentos gerais e profissionais de maneira que estas competências possam ser mensuradas por meio da realização de tarefas específicas (Burnier, 2001; Nunes \& Barbosa, 2009; Siqueira \& Nunes, 2011; McClelland, 1973; Brasil, 1996; Fleury \& Fleury, 2001).

A formação por competências trabalha no sentido de proporcionar ao educando a construção prática de operações mentais que o tornem capaz de agir concatenando seu saber, sua perícia e sua visão sobre determinada situação a qual está inserido, logrando êxito em relação ao problema enfrentado. Neste tipo de educação há a mudança do foco 'de reprodução de conhecimento' para 'desenvolvimento de competências', ou seja, a capacidade de aplicar conhecimentos em novos contextos e situações concretas (Perrenoud, 2000; Siqueira \& Nunes, 2011).

\subsubsection{Competências Empreendedoras}

McClelland (1961) inicialmente identificou três grupos de competências empreendedoras: proatividade, orientação para resultados e comprometimento. Contudo, foi Schumpeter (1934) quem relacionou o empreendedorismo (ou competências empreendedoras) a inovação e a capacidade de transformação ou "destruição criadora" relacionando ao desvio de comportamento usual de pessoas empreendedoras (McClelland, 1961; Schumpeter, 1934).

Parry (1996) referiu-se a competências como uma correlação entre conhecimento, habilidades e atitudes. Man e Lau (2000) baseados em estudos anteriores inovaram ao criar uma categorização de competências empreendedoras, como observa-se no Quadro 2 (Parry, 1996; Arnaut \& Pcchiai, 2016; Amaro \& Brunstein, 2013; Man \& Lau, 2000).

Quadro 2. Categorias de Competências Empreendedoras e suas Características

\begin{tabular}{|c|c|}
\hline Competência & Características relacionadas \\
\hline $\begin{array}{l}\text { Competências de } \\
\text { Oportunidade }\end{array}$ & $\begin{array}{l}\text { - Identificar oportunidades de negócios; } \\
\text { - Avaliar o ambiente econômico e oportunidades de negócios; } \\
\text { - Conduzir atividades de pesquisa e marketing para novas oportunidades. }\end{array}$ \\
\hline $\begin{array}{l}\text { Competências de } \\
\text { Relacionamento }\end{array}$ & $\begin{array}{l}\text { - Desenvolver redes de relacionamento e relacionamentos interpessoais de } \\
\text { longa duração; } \\
\text { - Utilizar-se das redes de relacionamento com diversos objetivos (novos } \\
\text { negócios, melhoria de habilidade, busca de informações, novas contratações } \\
\text { de pessoal especializado). }\end{array}$ \\
\hline $\begin{array}{c}\text { Competências } \\
\text { Conceituais }\end{array}$ & $\begin{array}{l}\text { - Ter perspicaz senso intuitivo para avaliar e tomar decisões; } \\
\text { - Demonstrar alta capacidade de observação; } \\
\text { - Analisar determinada situação de diferentes pontos de vista. }\end{array}$ \\
\hline
\end{tabular}

continua 


\begin{tabular}{|c|l|l|}
\hline \multicolumn{2}{|c|}{ Quadro 3. Categorias de Competências Empreendedoras e suas Características (continuação) } \\
\hline Competência & \multicolumn{1}{c|}{ Características relacionadas } \\
\hline Competências & - Planejar negócios e operações; \\
Administrativas & - Obter, de forma eficiente, recursos e habilidades para a organização; \\
\hline - Organizar, desenvolver, motivar, liderar e gerenciar os recursos humanos.
\end{tabular}
Fonte: Man e Lau (2000); Arnaut e Pcchiai (2016).

O desenvolvimento das competências empreendedoras pode ser uma forma de colaborar com a redução de mortalidade de empresas nascentes, trazer vantagem competitiva, gerar inovação, reduzir as desigualdades locais e regionais e, ainda, promover justiça social. Martins(2010) advoga que para se tornar um empreendedor basta qualificação pessoal e profissionalmente e a educação (básica, tecnológica ou acadêmica) pode ser um fator determinante para o empreendedorismo(Amaro\& Brunstein, 2013; Martins, 2010; Filion, 1999; Drucker, 1987; Coan, 2011).

\subsubsection{Empreendedorismo}

O termo empreendedorismo é originário da língua francesa entrepreneur, posteriormente traduzido para o inglês intrepreneurship, que significa "empreender" em português. Empreendedorismo era considerado o ato de empreender um negócio ou a criação de uma empresa principalmente coma função de gerar crédito, posteriormente o termo passou a qualificar a pessoa contratada por uma empresa que realiza um ofício especializado (Coan, 2011).

O tema foi estudado inicialmente pelos economistas com interesse em gerenciamento de negócios, novos empreendimentos e no desenvolvimento econômico propriamente dito, além da área da economia. Outro grupo de pesquisadores que se interessou pelo tema foram os chamados comportamentalistas que nas palavras de Filion $(1999$, p. 8) "refere-se aos psicólogos, sociólogos, e outros especialistas do comportamento humano" (Filion, 1999).

Ao longo dos anos pesquisadores dedicaram-se ao estudo do comportamento empreendedor na tentativa de identificar as principais características que influenciavam a decisão de empreender. O Quadro 4 traz algumas definições (Filion, 1999; Medeiros, 2012; D'alberto, 2005; Dornelas, 2017). 


\begin{tabular}{|c|c|}
\hline \multicolumn{2}{|r|}{ Quadro 3. Definições de Empreendedorismo } \\
\hline Autor & Definições \\
\hline $\begin{array}{l}\text { Mcclelland (1987, p. } \\
\text { 354) }\end{array}$ & $\begin{array}{l}\text { "Empreendedor é alguém que exerce controle sobre uma produção que não seja } \\
\text { só para o seu consumo pessoal" }\end{array}$ \\
\hline Drucker (1987, p. 63). & $\begin{array}{l}\text { "O trabalho específico do empreendedorismo numa empresa de negócios é fazer } \\
\text { os negócios de hoje capazes de fazer o futuro, transformando-se num negócio } \\
\text { diferente". "Empreendedorismo não é nem ciência, nem arte. É uma prática". }\end{array}$ \\
\hline $\begin{array}{l}\text { Schumpeter }(1997, \mathrm{p} . \\
123)\end{array}$ & $\begin{array}{l}\text { Empreender é "o processo de introdução de uma inovação no sistema econômico } \\
\text { pelo "empresário-empreendedor", visando a obtenção de lucro." }\end{array}$ \\
\hline Filion $(1999$, p. 21, 19) & $\begin{array}{l}\text { "o campo do empreendedorismo pode ser defino como aquele que estuda os } \\
\text { empreendedores" e que empreendedor é a "pessoa que imagina, desenvolve e } \\
\text { realiza visões". }\end{array}$ \\
\hline Dolabela (2011, p. 43) & $\begin{array}{l}\text { Empreendedor é a pessoa que se "dedica à geração de riqueza, seja na } \\
\text { transformação de conhecimentos em produtos ou serviços, na geração do próprio } \\
\text { conhecimento ou na inovação em áreas como marketing, produção, organização, } \\
\text { etc." }\end{array}$ \\
\hline Dornelas (2018, p. 8) & $\begin{array}{l}\text { Empreendedores "são pessoas diferenciadas que, possuem motivação singular, } \\
\text { são apaixonadas pelo que fazem, não se contentam em ser mais um na multidão, } \\
\text { querem ser reconhecidas e admiradas, referenciadas e imitadas, querem deixar } \\
\text { um legado". }\end{array}$ \\
\hline GEM (2016, p. 110), & $\begin{array}{l}\text { Empreendedorismo é "qualquer tentativa de criação de um novo negócio ou novo } \\
\text { empreendimento como, por exemplo, uma atividade autônoma, uma nova } \\
\text { empresa ou a expansão de um empreendimento existente". }\end{array}$ \\
\hline
\end{tabular}
Fonte: elaborado pelo autor.

Observa-se que o conceito sobre empreendedorismo difere, contudo em praticamente todas as definições são percebidas características comuns como: liderança, iniciativa, criatividade, autoconfiança, aceitação a riscos moderados, flexibilidade, orientação por resultados, autorrealização, comportamento e etc. A pesar de não possuir uma definição ortodoxa existe certo consenso entre os pesquisadores que aceitação a correr riscos e tendência a inovação dos empreendedores têm papel importante no desenvolvimento econômico (McClelland, 1987; Schumpeter, 1934; Drucker, 1987; GEM, 2016; SEBRAE, 2018; Filion, 1999; Fenando, 2011; Dornelas, 2018).

\section{Procedimentos Metodológicos}

A pesquisa é de natureza aplicada, pois busca criar conhecimento para aplicações práticas guiadas à solução de problemas específicos. Seu objetivo é exploratório visando trazer maior familiaridade ao problema com objetivo de aprimorar ideias ou construir novas hipóteses (Gil, 2002; Prodanov \& Freitas, 2013).

O procedimento é um estudo de caso, ou seja, uma pesquisa empírica que investiga um fenômeno moderno em seu contexto real buscando esclarecer os limites entre o fenômeno e seu contexto. (Yin, 2015).

Por se tratar de uma pesquisa exploratória inicialmente realizou-se uma análise documental de diversas fontes a qual Gil (2002, p. 45) afirma que "vale-se de materiais que não receberam um tratamento analítico, ou que ainda podem ser reelaborados de acordo com os objetivos da pesquisa" (Gil, 2002).

Realizou-se uma amostra intencional (Gil, 2002, p. 145) "em que os indivíduos são selecionados com base em certas características tidas como relevantes pelos pesquisadores e participantes, mostra-se mais adequada para obtenção de dados de natureza qualitativa".

\subsection{Análise Documental}


A análise dos PPCs dos cursos de graduação do universo selecionado foi realizada durante o ano de 2018, buscando as principais características e objetivos de cada curso, o perfil exigido do egresso, as habilidades e competências desejáveis dos formandos, a justificativa da necessidade do curso, a fundamentação teórico-metodológica e sua matriz curricular. O objeto de procura foi primeiramente pela disciplina "empreendedorismo", posteriormente palavras equivalentes ou que remetessem ao tema objeto de estudo.

Foram elencadas três informações básicas, na forma de questionamentos, que devem constar na pesquisa realizada nos PPCs de cada curso de graduação: 1) Os objetivos do curso possuem características empreendedoras?; 2) Exige-se do egresso um perfil empreendedor?; e 3) São exigidas Competências, Habilidades e Atitudes empreendedoras do egresso? Como resultado possível esperava-se encontrar uma resposta positiva (sim) ou negativa (não) para cada pergunta.

\subsection{Coleta de Dados e Informações Primárias: Entrevistas}

Para Duarte (2004, p. 215) "entrevistas são fundamentais quando se precisa/deseja mapear práticas, crenças, valores e sistemas classificatórios de universos sociais específicos, mais ou menos bem delimitados, em que os conflitos e contradições não estejam claramente explicitados" (Duarte, 2004).

As entrevistas foram realizadas com os coordenadores de cursos de graduação das faculdades selecionadas no decurso dos meses de outubro de 2018 e março de 2019. Utilizouse um roteiro semiestruturado seguindo uma sequência de perguntas previamente estabelecidas, mas que o entrevistado possui liberdade para expressar sua opinião. Esta espécie de questionário proporciona o levantamento de indícios, modos e informações relevantes, as quais procuram descrever e compreender as relações que se estabelecem no interior do grupo em análise (Gil, 2002; Marconi \& Lakatos, 2003; Duarte, 2004; Yin, 2015).

Inicialmente com base no universo objeto de estudo esperava-se entrevistar vinte e quatro coordenadores de cursos de graduação, contudo não foi possível realizar a entrevista com a coordenadora do curso de Química na modalidade Licenciatura, ou seja, foram realizadas no total vinte e três entrevistas.

O roteiro utilizado nas entrevistas foi elaborado em seção única contendo nove perguntas, sendo sete delas com a possibilidade de respostas abertas, ou seja, pretende-se extrair a opinião do entrevistado sobre o tema. Trata-se de um recorte de parte de uma dissertação de Mestrado, a qual possui os dados completos sobre a pesquisa (Zanchet, 2019).

O método aplicado foi misto, utilizando-se de aspectos qualitativos nas entrevistas com os coordenadores dos cursos de graduação investigando-se as percepções, as experiências, e as ações práticas dos entrevistados sobre o tema, bem como projetos de cooperação e/ou produtos desenvolvidos pelo o curso em questão. Para os aspectos quantitativos, buscou-se enumerar a quantidade de atividades de cunho empreendedor que são desenvolvidas dentro da UFGD e as características empreendedoras presentes nos PPCs dos cursos de graduação do universo selecionado (Amaral et al., 2018).

Cada entrevista com os coordenadores também teve como objetivo entender o papel desempenhado pelo profissional no momento da elaboração e implementação de uma nova matriz curricular pelo Núcleo Docente Estruturante (NDE). O NDE "constitui-se de um grupo de docentes, com atribuições acadêmicas de acompanhamento, atuante no processo de concepção, consolidação e contínua atualização do projeto pedagógico do curso" (UFGD, 2018). 
Geralmente, o coordenador do curso compõe o NDE da universidade, não necessariamente sendo uma regra. Como parte dos resultados das entrevistas averiguou-se que os docentes do NDE possuem autonomia limitada na inclusão de novas disciplinas que não sejam afetas ao curso.

As entrevistas foram previamente agendadas com os coordenadores e gravadas em áudio para posterior análise. A principal finalidade das entrevistas é obter respostas para as questões número IV a X do Quadro ${ }^{\circ} 10$. De posse do áudio, o pesquisador buscou sintetizar a informação manifestada pelo entrevistado durante a entrevista. Assim, realizando um exercício de ir e vir obteve-se as respostas para tais questões. Ressalta-se que inicialmente não se tratavam de respostas dicotômicas, sim ou não, mas de conceitos complexos sobre o tema. As respostas na forma que estão apresentadas são resultado da ideia central expressa pelo entrevistado.

\section{Educação Empreendedora na UFGD}

Com objetivo de avaliar o grau de cultura empreendedora dentro da UFGD fez-se a análise dos Projetos Pedagógicos de Cursos (PPCs) de graduação, entrevistas com os coordenadores dos cursos de graduação, análise do Plano de Desenvolvimento Institucional (PDI), mapeamento das atividades realizadas pela Divisão de Incubadoras e o mapeamento das principais atividades desempenhadas pelas Pró-reitorias de Graduação, Pós-graduação e Pesquisa e Extensão e Cultura.

\subsection{Pró-Reitorias}

As Pró-Reitorias podem ter atribuições administrativas e de assessoramento à Reitoria atuando nas atividades correspondentes à sua área específica. São divisões responsáveis por formular diagnósticos para os problemas da Instituição, elaborar políticas de atuação e coordenar as atividades (UFGD, 2018).Para os objetivos a que se destina esta pesquisa somente investigou-se os trabalhos desenvolvidos pelas PROGRAD, PROEX e PROPP.

\subsubsection{Pró-Reitoria de Graduação - PROGRAD}

A PROGRAD é responsável pelo planejamento, coordenação, execução, controle, supervisão e avaliação das atividades de ensino, assim como pela orientação, coordenação e avaliação das atividades didático-pedagógicas, subsidiando e assessorando os órgãos competentes na definição de políticas de ensino, além de estimular, viabilizar e fomentar a integração da Universidade, sugerindo mecanismos que favoreçam a melhoria de ensino (UFGD, 2018).

A principal atividade de caráter empreendedor desempenhada pela PROGRAD está relacionada em auxiliar e orientar os estudantes no processo de criação, manutenção e desenvolvimento de empresas juniores no âmbito da UFGD. O Quadro 6, relaciona todas as Empresas Juniores existentes na Universidade cujo principal objetivo é desenvolver o empreendedorismo entre os acadêmicos procurando relacionar a teoria aprendida em aula com a prática (UFGD, 2018). 


\begin{tabular}{|c|c|c|}
\hline \multicolumn{3}{|c|}{ Quadro 4. Empresas Juniores (EJ) constituídas na UFGD } \\
\hline Identificação & Faculdade e Curso de Graduação relacionado & Objetivos gerais das EJ \\
\hline Ínteri Júnior & $\begin{array}{l}\text { Empresa Júnior do Curso de Relações Internacionais } \\
\text { - FADIR }\end{array}$ & \multirow{9}{*}{$\begin{array}{l}\text { I - Desenvolver o lado profissional } \\
\text { dos estudantes que compõem a } \\
\text { empresa júnior; } \\
\text { II - Fomentar o conceito de } \\
\text { empreendedorismo nos estudantes, } \\
\text { lhes proporcionando: } \\
\text { a) Experiência profissional e } \\
\text { empresarial; } \\
\text { b) Aplicação prática do } \\
\text { conhecimento da respectiva } \\
\text { área de formação; } \\
\text { c) Oportunizando vivência no } \\
\text { marcado de trabalho; } \\
\text { d) Fornecendo à sociedade } \\
\text { retorno dos investimentos; } \\
\text { e) Prestando serviços as micro } \\
\text { e pequenas empresas; } \\
\text { f) Contribuindo para o } \\
\text { desenvolvimento econômico } \\
\text { e social; } \\
\text { g) Intensificando a relação } \\
\text { sociedade/universidade. }\end{array}$} \\
\hline JEEAGRI & $\begin{array}{l}\text { Empresa Júnior do Curso de Engenharia Agrícola - } \\
\text { FCA }\end{array}$ & \\
\hline $\begin{array}{l}\text { Terra Fértil } \\
\text { Soluções } \\
\text { Agrícolas }\end{array}$ & Empresa Júnior do Curso de Agronomia - FCA & \\
\hline SIGMAX & $\begin{array}{l}\text { Empresa Júnior do Curso de Engenharia de } \\
\text { Produção - FAEN }\end{array}$ & \\
\hline EJIPTA & $\begin{array}{l}\text { Empresa Júnior do Curso de Engenharia de } \\
\text { Alimentos - FAEN }\end{array}$ & \\
\hline $\mathrm{J} 3 \mathrm{E}$ & $\begin{array}{l}\text { Empresa Júnior do Curso de Engenharia de Energia } \\
\text { - FAEN }\end{array}$ & \\
\hline $\begin{array}{l}\text { Kaizen } \\
\text { Consultoria } \\
\text { Júnior }\end{array}$ & Empresa Júnior do Curso de Psicologia - FCH & \\
\hline $\begin{array}{l}\text { Unus } \\
\text { Consultoria }\end{array}$ & $\begin{array}{l}\text { Empresa Júnior dos Cursos de Biotecnologia, } \\
\text { Gestão Ambiental e Ciências Biológicas - FCBA }\end{array}$ & \\
\hline $\begin{array}{l}\text { Triunity } \\
\text { Júnior }\end{array}$ & $\begin{array}{l}\text { Empresa Júnior dos Cursos de Administração, } \\
\text { Ciências Contábeis e Economia - FACE }\end{array}$ & \\
\hline
\end{tabular}

Fonte: PROGRAD (UFGD, 2018), elaborado pelo autor.

\subsubsection{Pró-Reitoria de Pós-graduação e Pesquisa - PROPP}

A PROPP é um órgão executivo que tem como missão o planejamento, a orientação, acompanhamento e avaliação das atividades de pesquisa, iniciação científica e pós-graduação. Também trabalha na coordenação e orientação das atividades de Pesquisa e Pós-Graduação Lato e Stricto Sensu buscando promover a articulação com a comunidade, com outras Universidades e com órgãos e entidades públicas e privadas (UFGD, 2018). Não foram encontradas atividades e/ou programas com caráter empreendedor desenvolvidas pela PROPP.

\subsubsection{Pró-Reitoria de Extensão e Cultura - PROEX}

A PROEX possui a responsabilidade de coordenar e acompanhar as ações de extensão e cultura da UFGD, também é responsável por parte das licitações referentes a serviços ligados às ações de extensão e de cultura, orientação a professores, alunos e técnicos da universidade com o objetivo de otimizar as ações e meios para a execução de atividades de extensão e cultura (UFGD, 2018).

A Coordenadoria de Extensão - COEX - disponibilizou informação sobre atividades de extensão com características empreendedoras. Estes dados estão sintetizados no Quadro 5. 


Quadro 5. Atividades de Extensão com Caráter Empreendedor Desenvolvidas pela PROEX
\begin{tabular}{|c|c|l|}
\hline \multicolumn{2}{|c|}{ Período } & \multicolumn{1}{c|}{ Tipo de atividade } \\
\hline 1 & $01 / 03 / 2010$ a $31 / 12 / 2010$ & $\begin{array}{l}\text { Utilização da apicultura como alternativa para a geração de renda nos } \\
\text { assentamentos da região de Dourados - MS }\end{array}$ \\
\hline 2 & $01 / 01 / 2013$ a $31 / 12 / 2013$ & $\begin{array}{l}\text { Uso e conservação da biodiversidade do cerrado: oportunidades de geração } \\
\text { de renda para os assentamentos rurais do município de Ponta Porã }- \text { MS }\end{array}$ \\
\hline 3 & $14 / 06 / 2013$ a $04 / 09 / 2013$ & $1^{\circ}$ Workshop da central de empresas juniores da UFGD \\
\hline 4 & $01 / 01 / 2015$ a $31 / 12 / 2016$ & Aquaponia: geração de renda para a agricultura familiar \\
\hline 5 & $11 / 04 / 2017$ a $27 / 07 / 2017$ & $\begin{array}{l}2^{\circ} \text { Workshop da central de empresas juniores da UFGD e } 1^{\circ} \text { Concurso de } \\
\text { vídeo Picht das empresas juniores da UFGD }\end{array}$ \\
\hline 6 & $01 / 01 / 2017$ a $31 / 12 / 2018$ & $\begin{array}{l}\text { Apicultura orgânica e agroecológico: alternativa de alimento e agregação de } \\
\text { renda na Agricultura Familiar }\end{array}$ \\
\hline 7 & $01 / 01 / 2017$ a $31 / 12 / 2018$ & $\begin{array}{l}\text { Mulheres assentadas e cooperadas na produção de alimentos saudáveis e } \\
\text { produtos de geração de renda na agricultura familiar }\end{array}$ \\
\hline 8 & $20 / 03 / 2017$ a $31 / 12 / 2018$ & $\begin{array}{l}\text { Espaço de comercialização de produtos Ecosociais na UFGD: inclusão } \\
\text { produtiva de grupo de mulheres assentadas e incubadas }\end{array}$ \\
\hline
\end{tabular}
Fonte: PROEX, UFGD (2018).

\subsection{Plano de Desenvolvimento Institucional - PDI}

O PDI é um instrumento de planejamento de longo prazo (cinco anos) elaborado por uma IES no qual estão definidos a missão, os objetivos e as metas da instituição, para um determinado período, bem como as ações para concretização de seu planejamento estratégico (Brasil, 2017; UFGD, 2013).

Até a data da realização desta pesquisa o PDI-UFGD que se encontra vigente abrange o quinquênio 2013-2017, prescrevendo que os cursos de graduação estão direcionados a enfrentar os principais problemas que inibem o desenvolvimento social, econômico e cultural além de atuar na preservação do meio ambiente. Procurando aprimorar esse desenvolvimento o PDI estimula a relação Universidade-Empresa com economias sociais e solidárias não somente na região de Dourados, mas também na Região da fronteira oeste (UFGD, 2013; PDI-UFGD, 2013).

O PDI-UFGD trata sobre a estruturação do Núcleo de Inovação e Propriedade Intelectual (NIPI), a Incubadora Empresarial e Tecnológica (GDTec) e implementação de Empresas Júniores dentro das diversas faculdades (UFGD, 2013; PDI-UFGD, 2013).

Também tem como objetivo a inclusão social, a geração de trabalho e renda, a promoção do desenvolvimento, da sustentabilidade socioambiental para a transformação efetivada sociedade, incentivando a união de esforços entre organizações da sociedade civil, iniciativa privada, governo e instituições de ensino e pesquisa. No que tange à área de atuação da Universidade o PDI não faz referência a qualquer ao empreendedorismo (UFGD, 2013; PDI-UFGD, 2013).

\subsection{Divisão de Incubadoras da UFGD}

A Incubadora de Empresas é um órgão contemplado pela Lei $n^{\circ} 10.973 / 2004$, tida como uma organização para prestar apoio logístico, gerencial e tecnológico ao empreendedorismo inovador com o "objetivo de facilitar a criação e o desenvolvimento de empresas que tenham como diferencial a realização de atividades voltadas à inovação" (Vedovello \& Figueiredo, 2005; Brasil, 2004; Antunes et al., 2019).

A Divisão de Incubadoras da UFGD organiza eventos, workshops e amostras com objetivo de divulgar o que está sendo desenvolvido dentro de suas incubadoras e realiza o 
planejamento, a gestão e a execução de ações para elevar o nível dos projetos(UFGD, 2017; UFGD, 2018).

A Incubadora de Empresas de Base Tecnológica (GDTec) busca disponibilizar mecanismos que oportunizem a alavancagem de empreendimentos inovadores de base tecnológica, trabalhar de maneira a integrar a universidade e a sociedade local, e regional caso seja necessário, visando o desenvolvimento de atividades empreendedoras, de inovação e de tecnologia(UFGD, 2017).O principal foco da GDTec é desenvolver projetos tecnológicos de universitários e da sociedade, voltados para inovação e que procurem melhorar as condições de vida e trabalho existentes (UFGD, 2017; UFGD, 2019)

A Incubadora de Tecnologias Sociais e Solidárias ITESS/UFGD, desenvolve ações com Empreendimentos de Economia Solidária (EES) nos âmbitos social, econômico e político, pautadas em princípios de economia solidária. As ações da Incubadora envolvem grupos em situação social e economicamente vulneráveis, mediadas por princípios cooperativos e solidários na busca da construção de mecanismos de melhoria de vida e inclusão social. Articula a execução de projetos a partir de demandas locais e regionais, voltados a sustentabilidade socioambiental, visando geração de trabalho e renda para grupos em situação de vulnerabilidade (UFGD, 2019).

A incubadora Cultural EKO a fortalece culturalmente a UFGD e região, com objetivo apoiar o desenvolvimento de empreendimentos culturais em seus estágios iniciais oferecendo serviços de apoio técnico ao empreendedor cultural, principalmente, com a redução de custos. A EKO a permite que empreendimentos culturais, com foco nas micro e pequenas iniciativas, recebam consultorias, assessorias e capacitações, bem como assessoria para captação de recursos e enquadramento dentro da Lei Rouanet (UFGD, 2019).

\subsection{Faculdades Objeto da Pesquisa}

A escolha do universo de pesquisa teve como base as Faculdades da UFGD que disponibilizam cursos de graduação na modalidade de Bacharelado, visto que algumas áreas como engenharias, sistemas de informação, ciências agrárias, administração e economia exigem do acadêmico um perfil empreendedor. Algumas faculdades oferecem curso de graduação nas modalidades de bacharelado e licenciatura, para estes casos específicos foram realizados estudos em ambas as categorias de graduação.

Foram pesquisados os cursos de graduação das Faculdade de Administração, Ciências Contábeis e Economia (FACE), Faculdade de Ciências Agrárias (FCA), Faculdade de Ciências Biológicas e Ambientais (FCBA), Faculdade de Ciências Exatas e Tecnologia (FACET), Faculdade de Direito e Relações Internacionais (FADIR) e Faculdade de Engenharia (FAEN).

O Quadro 6, reúne informações referentes a quais cursos de graduação e respectivas Faculdades que disponibilizam a disciplina de Empreendedorismo na matriz curricular.

Quadro 6. Faculdades Objeto da Pesquisa

\begin{tabular}{|c|c|c|c|c|c|c|}
\hline & \multicolumn{7}{|c|}{ Faculdades } \\
\hline Objeto de estudo & FACE & FCA & FCBA & FACET & FADIR & FAEN \\
\hline $\begin{array}{c}\text { Cursos que } \\
\text { possuem a } \\
\text { disciplina de } \\
\text { empreendedorismo }\end{array}$ & Administração & - & $\begin{array}{c}\text { Sistemas de } \\
\text { Gestão } \\
\text { Informação } \\
\text { e Engenharia } \\
\text { da } \\
\text { Computação }\end{array}$ & - & $\begin{array}{c}\text { Engenharia } \\
\text { de } \\
\text { Produção e } \\
\text { Engenharia } \\
\text { de Energia }\end{array}$ \\
\hline
\end{tabular}

Fonte: elaborado pelo autor. 
Identificou-se que somente os cursos de graduação de Administração (FACE), Gestão Ambiental (FCBA), Sistemas de Informação e Engenharia da Computação (FACET) e Engenharia de Produção e de Energia (FAEN) disponibilizam a disciplina de empreendedorismo para os acadêmicos.

\section{Análise dos Resultados}

A análise dos resultados procura responder às questões-problema elencadas no início deste artigo.

\subsection{Política Institucional de Educação Empreendedora na UFGD}

Constatou-se que são exigidos dos acadêmicos diversas características e competências empreendedoras, entretanto apenas os cursos constantes no Quadro 7 possuem a disciplina de empreendedorismo como obrigatória e/ou equivalente em suas grades curriculares. Destaca-se que alguns coordenadores dos cursos da modalidade Licenciatura acreditam que o objetivo do curso é a formação de docentes e não veem a inclusão da disciplina de empreendedorismo na matriz curricular como prioridade. Por sua vez, outros docentes afirmam que o excesso de disciplinas obrigatórias impede a inclusão de novas.

Quadro 7. Cursos de Graduação da UFGD que possuem a Disciplina de Empreendedorismo

\begin{tabular}{|c|c|c|}
\hline $\begin{array}{c}\text { Curso de } \\
\text { Graduação }\end{array}$ & $\begin{array}{c}\text { Ementa da disciplina de Empreendedorismo } \\
\text { no respectivo PPC } \\
\end{array}$ & $\begin{array}{c}\text { Data da inclusão da disciplina no } \\
\text { curso }\end{array}$ \\
\hline Administração & (PPC Administração, 2014, p. 45). & Ano letivo de 2015 \\
\hline $\begin{array}{l}\text { Sistemas de } \\
\text { Informação }\end{array}$ & (PPC Sistemas de Informação, 2017, p. 51). & Ano letivo de 2016 \\
\hline $\begin{array}{l}\text { Engenharia de } \\
\text { Computação }\end{array}$ & (PPC Eng Computação, 2016, p. 53). & Ano letivo de 2017 \\
\hline $\begin{array}{l}\text { Engenharia de } \\
\text { Produção }\end{array}$ & (PPC Eng Produção, 2017, p. 110). & Ano letivo de 2018 \\
\hline $\begin{array}{c}\text { Engenharia de } \\
\text { Energia }\end{array}$ & (PPC Eng Energia, 2017, p. 104 e 105). & Ano letivo de 2018 \\
\hline Gestão Ambiental & (PPC Gestão Ambiental, 2014, p. 41). & Ano letivo de 2015 \\
\hline
\end{tabular}

Fonte: (UFGD, 2020); elaborado pelo autor.

Com base na análise dos dados extraídos do PDI-UFGD, Pró-reitorias e Entrevistas observa-se que a UFGD não possui uma política institucional voltada ao ensino do empreendedorismo. Contempla atividades incipientes e isoladas, desenvolvidas pelos coordenadores dos cursos de graduação. Garrido Filho et al. (2009, p. 2) afirmam que a "institucionalização representa um processo condicionado pela conformidade às normas socialmente aceitas, bem como pela incorporação de um sistema de conhecimento construído ao longo da interação social, os quais constituem parâmetros para concepção de realidade dos atores sociais e para a ação" (Garrido Filho et al., 2009).

\subsection{Percepção do Tema 'Empreendedorismo' nos Cursos de Graduação da UFGD}

O tema é visto de maneira favorável pelos coordenadores dos cursos entrevistados. A compreensão sobre o ensino do empreendedorismo diverge conforme o docente, desde desenvolver novas ideias, novos modelos de negócios, observar as necessidades de mercado com propósito remuneratório ou de realização profissional, formar no egresso senso crítico, fortalecer a criatividade, o espírito desafiador, buscar oportunidades, ser persistente, correr riscos calculados, estar comprometido com o empreendimento, primar pela qualidade e eficiência, ter metas estabelecidas e claras, ter autoconfiança, entre outros. 
Nas graduações que não possuem disponibilidade da disciplina de empreendedorismo o tema é apresentado aos acadêmicos durante a realização de Semanas Acadêmicas, Simpósios, Minicursos, Palestras, Workshop, pela Empresa Júnior e parcerias UniversidadeEmpresas. Há que se destacar que alguns cursos como os de Licenciatura não possuem Empresa Júnior, não promovem ações práticas voltadas ao empreendedorismo e também tem tido dificuldade em realizar semanas acadêmicas.

\subsection{Agenda de Pesquisa e Extensão sobre Empreendedorismo na UFGD}

Recorreu-se aos dados fornecidos pelas Pró-reitorias (PROGRAD, PROPP e PROEX) e ao PDI-UFGD. A principal atividade de caráter empreendedor desenvolvida pela PROGRAD está relacionada no auxílio e orientação de estudantes no processo de criação, manutenção e desenvolvimento de Empresas Juniores no âmbito da UFGD, sendo atualmente 9 (nove) Empresas Juniores em funcionamento na UFGD.

Não foram encontradas atividades relevantes desenvolvidas pela PROPP no sentido de desenvolver ou estimular o ensino do empreendedorismo dentro da universidade. Foram identificadas 8 (oito) atividades (Quadro 7) de caráter empreendedor coordenadas pela PROEX. As atividades dos itens 1, 2 e 4, foram descontinuadas, não sendo identificadas as razões para seu encerramento. As atividades $3,5,6,7$ e 8 continuam em funcionamento(UFGD, 2018)

O PDI incentiva a preparação do aluno à resolução de problemas concretos vivenciados pelas sociedades empresárias e a comunidade em geral, estimulando o desenvolvimento socioeconômico e cultural da região. Contempla o Núcleo de Inovação e Propriedade Intelectual (NIPI), a Incubadora Empresarial e Tecnológica (GDTec) e as Empresas Júniores. Contudo não traz menção alguma a atuação empreendedora da universidade (UFGD, 2013; UFGD, 2013; UFGD, 2017).

\subsection{Metodologias e Práticas Pedagógicas utilizadas pelos Gestores para Implantar, Estimular e Intensificar a Educação Empreendedora}

Os cursos de graduação que possuem a disciplina de empreendedorismo em suas grades curriculares seguem as diretrizes curriculares prescritas nas ementas dos respectivos PPCs. Observou-se que principalmente os cursos de Administração, Gestão Ambiental e Engenharia de Produção procuram estimular o acadêmico a buscar soluções para problemas concretos desenvolvendo métodos e competências que estimulem o pensamento empreendedor. Os demais cursos se utilizam basicamente de semanas acadêmicas, simpósios, palestras com profissionais empreendedores que são referência em suas áreas, Empresas Júniores e parcerias Universidade-Empresas para apresentar a disciplina aos acadêmicos.

Constatou-se que atividades de desenvolvimento de empreendedorismo dentro da UFGD são esporádicas e/ou sazonais. Não existe uma agenda metodológica permanente de atividades desenvolvidas pelas Faculdades e/ou pelos coordenadores dos cursos para promoção de atividades empreendedoras.

\subsection{Síntese das Informações Extraídas dos PCC e Entrevistas}

O Quadro 8 está dividido em duas partes, a primeira refere-se a informações presentes nos PPCs dos Cursos de Graduação e a segunda informações extraídas das entrevistas realizadas com os Coordenadores dos Cursos de Graduação. 
Quadro 8. Informações extraídas dos PPCs e entrevistas com os Coordenadores de Cursos de Graduação

\begin{tabular}{|c|l|}
\hline \multirow{2}{*}{ PPC } & $\begin{array}{l}\text { I) Os objetivos do curso possuem características empreendedoras?; II) Exige-se do egresso } \\
\text { um perfil empreendedor?; e III) Exige competências, habilidades e competências } \\
\text { empreendedoras? }\end{array}$ \\
\hline \multirow{5}{*}{ ENTREVISTAS } & $\begin{array}{l}\text { IV) O coordenador do curso possui visão favorável ao tema empreendedorismo? V) O } \\
\text { coordenador do curso possui experiências pessoal ou profissional na área do } \\
\text { empreendedorismo?; VI) Existe disciplina específica sobre o tema empreendedorismo } \\
\text { ministrada no curso?; VII) Existem ações práticas voltadas ao empreendedorismo dentro } \\
\text { do curso?; VIII) A disciplina de empreendedorismo é estratégica/importante para o curso? } \\
\text { IX) Existem projetos de colaboração/cooperação com empresas visando o estímulo ao } \\
\text { empreendedorismo?; e X) O curso criou algum produto, projeto ou serviço que possa ser } \\
\text { considerado inovador? }\end{array}$ \\
\hline
\end{tabular}

Fonte: elaborado pelo autor.

O Quadro 9 apresenta a ordem de distribuição do Curso de graduação dentro de sua respectiva Faculdade.

Quadro 9. Distribuição dos Cursos de Graduação por Faculdade

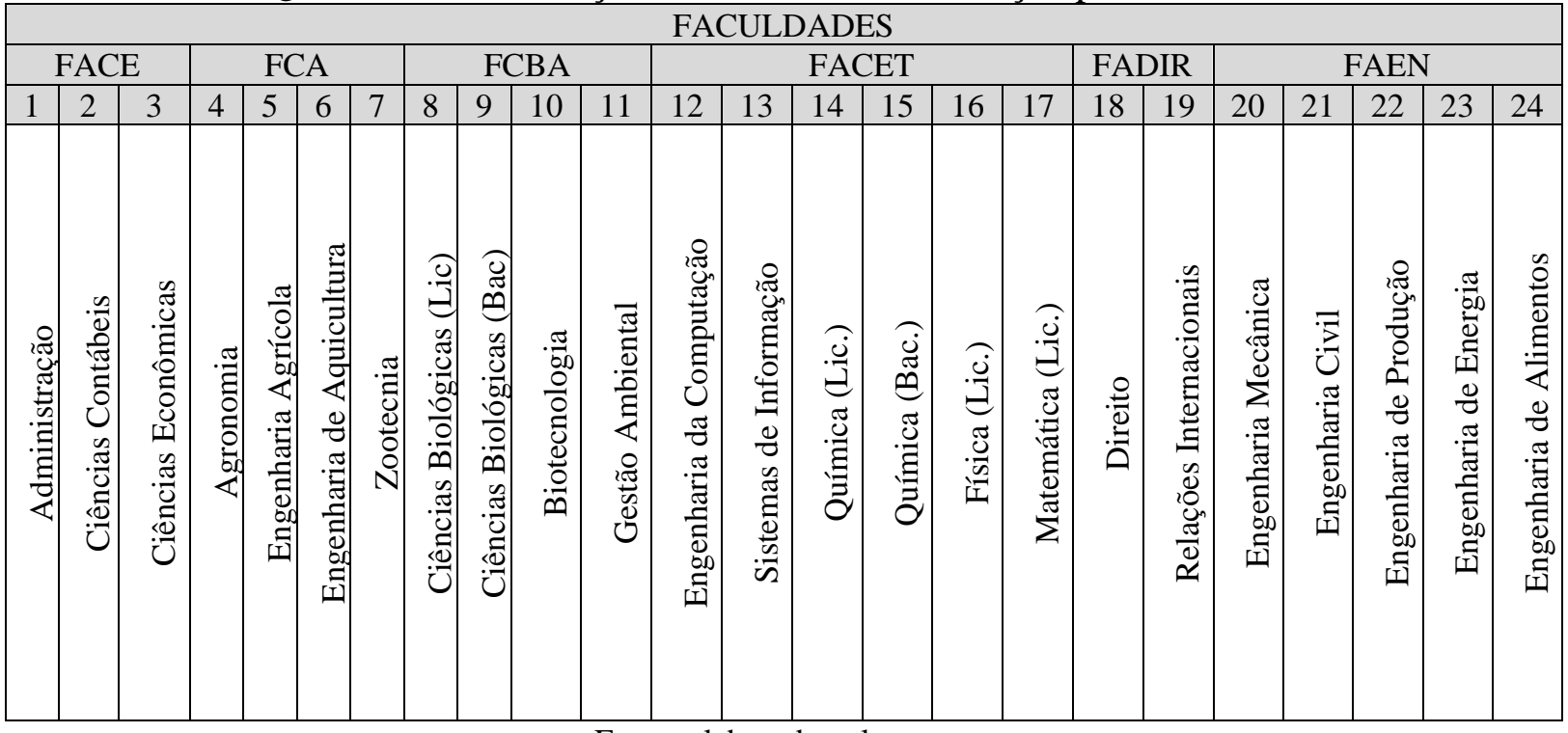

Fonte: elaborado pelo autor.

O Quadro 10 traz a distribuição das informações-síntese coletadas referente às principais características analisadas tanto dos PPCs quantos das entrevistas com os Coordenadores dos Cursos de Graduação. Deve-se ressaltar que as respostas para os questionamentos apresentados no Quadro 8, não podem ser consideradas simplesmente dicotômicas, no entanto para fins mensuráveis buscou-se traduzir o objetivo final do pensamento do entrevistado. Como resultado possível, para cada pergunta do Quadro 8, esperava-se encontrar uma resposta positiva (sim) ou negativa (não).

Exemplificando; para o questionamento "I) Os objetivos do curso possuem características empreendedoras?" do Quadro 8, contido na análise do PPC de Administração da FACE, têm-se uma resposta positiva "S", sim. 
Quadro 10. Síntese da análise dos PPCs e entrevistas com os Coordenadores de Cursos de Graduação

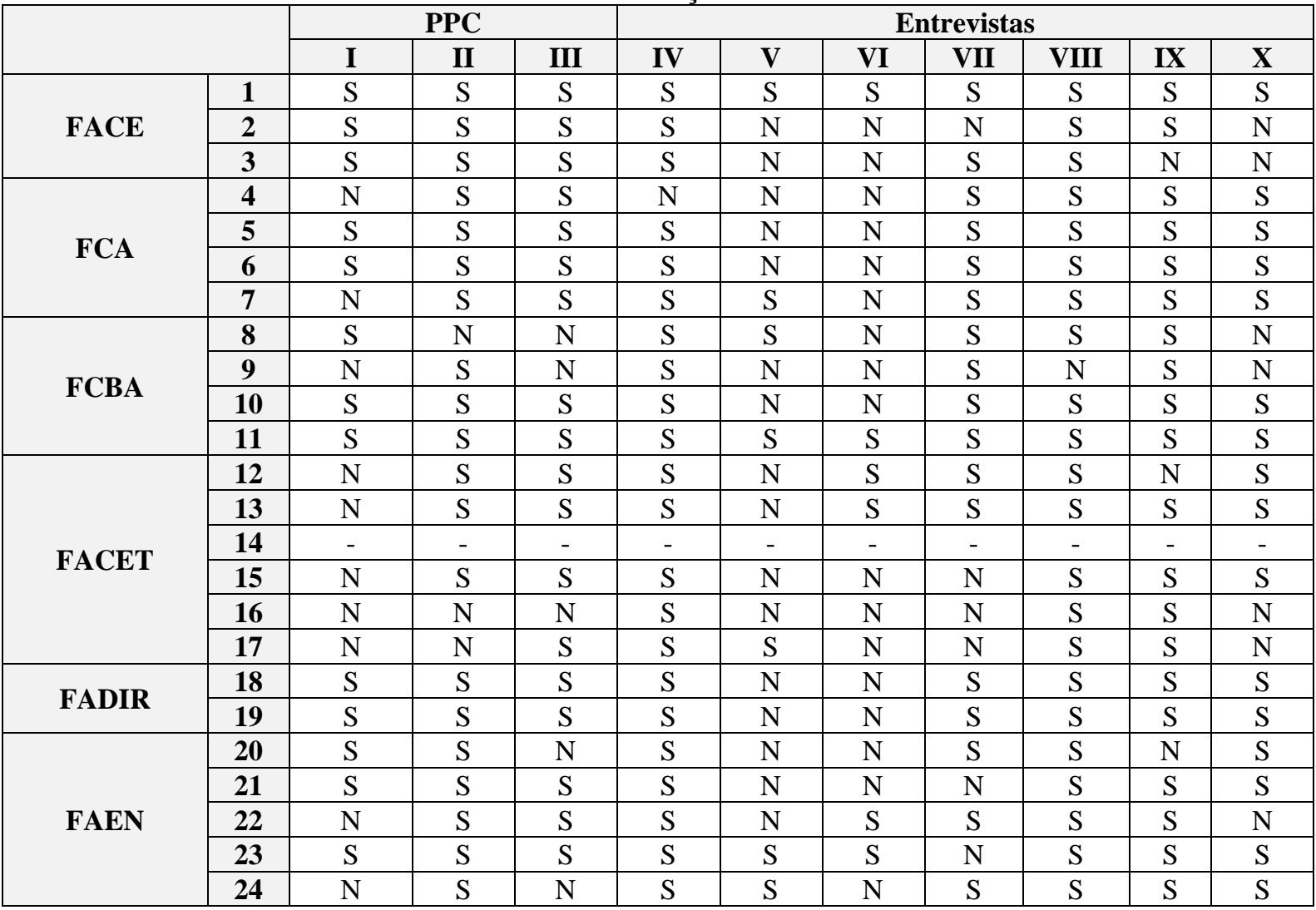

Legenda: S (Sim), N (Não).

Fonte: (UFGD, 2020) e Entrevistas realizadas com os coordenadores de cursos de graduação da FACE, FCA,

FCBA, FACET, FADIR e FAEN; elaborado pelo autor.

Para elaborar o Gráfico 1, utilizou-se os dados tabulados constantes do Quadro 10, inicialmente o quadro foi reconstruído em formato de planilha eletrônica de cálculo, com os dados divididos em dois grupos conforme Quadro 8.

Para cada resposta positiva, onde antes constava "sim", atribuiu-se o valor numérico "um", e para cada resposta negativa, onde antes constava "não" o valor numérico "zero". Desta forma foi possível criar um gráfico no qual elencou-se dez características essencialmente empreendedoras nos cursos de graduação Quadro 8.

Após o preenchimento de cada característica com valores numéricos positivos (um) ou negativos (zero), gerou-se o gráfico de barras o qual traz a informação de quantas das dez características empreendedoras elencadas no Quadro 8 estão presentes em cada curso de graduação objeto do estudo. Por exemplo, os cursos de graduação em Gestão Ambiental e Administração possuem dez das dez características enumeradas como empreendedoras, 0 curso de Física - Licenciatura apresenta apenas três de dez características consideradas empreendedoras. 
Gráfico 1. Características empreendedoras extraídas da análise dos PPCs e entrevistas com os coordenadores de cursos de graduação

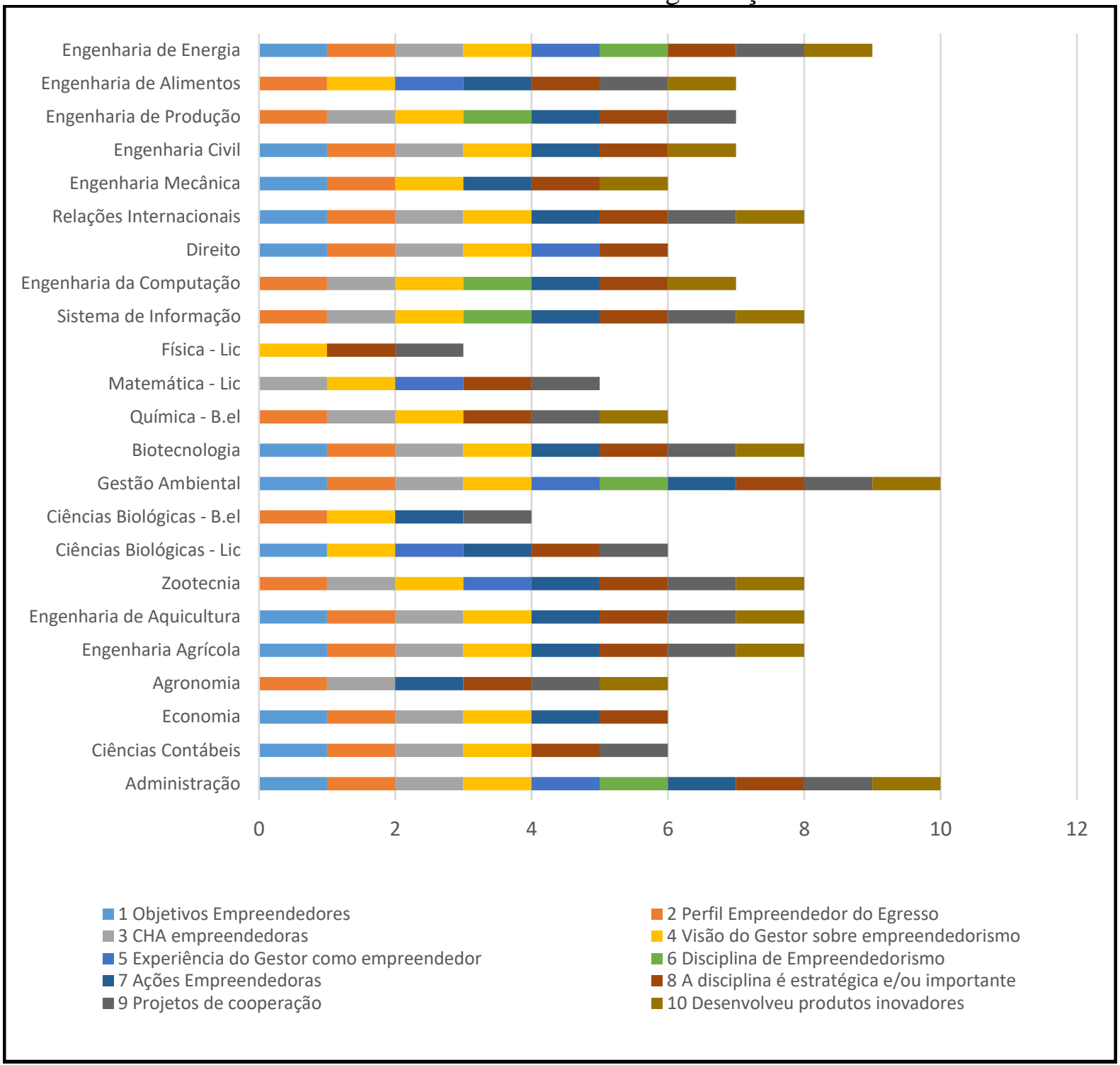

Fonte: elaborado pelo autor.

\section{Considerações Finais}

O presente artigo pretende contribuir para disseminação do tema 'empreendedorismo' e conscientização de sua importância para universidade, governo e sociedade. A pesquisa foi realizada sob a forma de um estudo de caso onde buscou-se entender a percepção dos docentes sobre o tema e quais as principais dificuldades enfrentadas dentro da UFGD para se implementar uma educação com viés empreendedor.

Verificou-se junto às Pró-reitorias a existência de projetos de desenvolvimento do ensino, pesquisa, graduação, pós-graduação e extensão que procuram promover a agenda empreendedora. Tanto a PROGRAD quanto a PROEX possuem projetos destinados a fomentar a cultura empreendedora entre os acadêmicos. A PROGRAD foca sua atividade na promoção e manutenção das Empresas Juniores. A PROEX desenvolve atividades de 
extensão de caráter empreendedor, algumas destas estão desativadas e outras em plena atividade.

Durante as entrevistas constatou-se que o tema é visto como importante, contudo, muitos coordenadores não veem a possiblidade de inserir a disciplina na matriz curricular devido a motivos como rigidez legislativa, núcleo de disciplinas obrigatórias e dificuldade de aplicabilidade prática da disciplina, principalmente em áreas de licenciatura.

Nos cursos em que a disciplina é ofertada na matriz curricular o acadêmico adquire conhecimento mais aprofundado. Observou-se que alguns cursos como Sistemas de Informação e Engenharia da Computação realizam projetos curriculares juntamente com outros cursos como Administração e Gestão Ambiental. Os docentes que ministram a disciplina são responsáveis por essa interação entre os diferentes cursos, não sendo uma política instituída pela UFGD.

Nos cursos que não possuem a disciplina na matriz curricular, mas o coordenador percebe a importância do tema para o acadêmico o assunto é apresentado por meio de abordagens em semanas acadêmicas e/ou em disciplinas correlatas.

Constatou-se que a UFGD possui uma cultura empreendedora que necessita de amadurecimento, visto que a maioria dos cursos objeto da investigação desenvolvem atividades empreendedoras de maneira isolada e esporádica. Os cursos de Administração, Gestão Ambiental, Sistemas de Informação, Engenharia da Computação, Engenharia de Energia e Engenharia da Produção possuem previsão em suas grades curriculares a disciplina de empreendedorismo, estes, pode-se considerar, estão no segundo estágio de implementação da cultura empreendedora.

Pode-se dizer que o processo de institucionalização da educação voltada ao empreendedorismo na UFGD ainda é pouco desenvolvido, existindo, portanto, espaço para melhoria desta nova metodologia educacional.

O presente trabalho possui limitações, por se tratar de um estudo de caso único e pontual apresenta a dificuldade de generalizações. Sua natureza exploratória apesar de valorizar as experiências vividas pode trazer o risco de o pesquisador deixar-se direcionar por vieses pessoais. A escolha do universo selecionado foi realizada por meio da amostra intencional, fato que pode acarretar distorção no momento da coleta e análise dos dados.

\section{Referências}

Albuquerque, C. P., Ferreira, J. S., \& Brites, G. (2016). Educação Holística para o Empreendedorismo: Uma Estratégia de Desenvolvimento Integral, de Cidadania e Cooperação. Revista Brasileira de Educação, 21(67), 1033-1056.

Amaral, M., Hernandez, C. T., \& Bastos, M. H. R. (2018). The entrepreneurial profile of Brazilan business administration students. International Journal of Innovation Science, 160-177.

Amaro, R. D., \& Brunstein, J. (2013). Implicações das Concepções de Empreender para o Desenvolvimento da Competência Empreendedora. Revista de Administração FACES, Journal Belo Horizonte, 12(4), 9-29.

Antunes, L. G., Souza, T. A., Silva, J. P., Lopes, G. C., \& Sugano, J. Y. (2019). Modelo de Negócio de Incubadora de Empresas: Revisão de Escopo. Revista de Administração, Sociedade e Inovação, 144-161. 
Arnaut, P. G., \& Pcchiai, D. (2016). Competências Empreendedoras: Modelos Mentais como Fatores Determinantes de seu Desenvolvimento. Revista Ciência Hermes, 16, 197-222.

Brasil. (1996). Lei de Diretrizes e Bases da Educação Nacional. Presidência da República, Brasília.

Brasil. (1996). Lei no 9.394 - Estabelece as Diretrizes e Bases da Educação Nacional, 20 de dezembro de 1996. Acesso em: 05 de janeiro de 2019. Disponível em: Planalto.

Brasil. (2004). Lei 10.973, de 2 de dezembro de 2004. Dispõe sobre Incentivos à Inovação e à Pesquisa Científica e Tecnológica no Ambiente Produtivo e dá outras Providências.

Brasil. (2011). Programa Nacional de Acesso ao Ensino Técnico e Emprego. Brasília/DF.

Brasil. (2017). Decreto $n^{\circ}$ 9.235, de 15 de dezembro de 2017. Acesso em: 17 de abril de 2019. Disponível em: http://www.planalto.gov.br/ccivil_03/_Ato20152018/2017/Decreto/D9235.htm\#art107

Burnier, S. (2001). Pedagogia das Competências: Conteúdos e Métodos. Boletim Técnico, 27(3).

Castro, M. H. (2011). Universidades e Inovação: Configurações Institucionais \& Terceira Missão. Caderno CRH, 24(63), 555-573.

Coan, M. (2011). Educação para o Empreendedorismo: Implicações Epistemológicas, Políticas e Práticas. Universidade Federal de Santa Catarina, Florianópolis/SC.

D'alberto, A. M. (2005). O Ensino do Empreendedorismo nos Cursos de Turismo do Estado de Santa Catarina, Brasil. Universidade Regional de Blumenal, Blumenal.

Daniel, A. D., Cerqueira, C., Ferreira, J. J., Preto, M. T., Afonso, P., \& Quaresma, R. (2015). Ensino do Empreendedorismo - Teoria e Prática. Em Universidade empreendedora no Contexto Português: Das Políticas Públicas ao Projeto GAPI3, 109-125.

Dias, A. A., \& Porto, G. S. (2014). Como a USP Transfere Tecnologia? Revista O\&S, 21(70), 489-508.

Dolabela, F., \& Filion, L. J. (2013). Fazendo Revolução no Brasil: A Introdução da Pedagogia Empreendedora nos Estágios Iniciais da Educação. Revista de Empreendedorismo e Gestão de Pequenas Empresas (REGEPE), 3(2), 134-181.

Dornelas, J. (2017). Impacto da Empresa Júnior na Intenção de Empreender dos Universitários Brasileiros. Fundação Getúlio Vargas, Rio de Janeiro.

Dornelas, J. (2018). Empreendedorismo: Transformando Ideias em Negócios. $7^{\text {a }}$ edição, São Paulo: Empreende. Pioneira.

Drucker, P. F. (1987). Inovação e Espírito Empreendedor. 5a edição, São Paulo:

Duarte, R. (2004). Entrevistas em Pesquisas Qualitativas. Educar, 24, 213-225.

Dutra, J. D. (2017). Competências: conceitos, instrumentos e experiências. $2^{a}$ edição, São Paulo: Atlas. 
Etzkowitz, H., \& Leydesdorff, L. (1995). The Triple Helix - University-IndustryGovernment Relations: A Laboratory for Knowledge based Economic Development. EASST Review, 14, 14-19.

Etzkowitz, H., \& Leydesdorff, L. (2000). The Dynamics of Inovation: From National Sistems and "Mode2" to a Triple Helix of University-Industry-Governament Relations. Research Policy, 29(2), 109-123.

Fenando, D. (2011). Oficina do Empreendedor. Rio de Janeiro: Sextante.

Filion, L. J. (1999). Empreendedorismo: Empreendedores e Proprietários-Gerentes de Pequenos Negócios. Revista de Administração, 34(2), 05-28.

Fleury, M. T., \& Fleury, A. (2001). Construindo o Conceito de Competência. Revista de Administração Contemporânea- RAC(Especial), 183-196.

Garrido Filho, E. R., Machado-da-Silva, C. L., \& Gonçalves, S. A. (2009). Institucionalização da Teoria Institucional no contexto dos estudos organizacionais no Brasil. XXXIII EnANPAD.

GEM. (2016). Global Enterpreneurship Monitor. Instituto Brasileiro de Qualidade e Produtividade, Curitiba/PR.

Gil, A. C. (2002). Como Elaborar Projetos de Pesquisa.4a edição, São Paulo: Atlas.

Le Boterf, G. (1995). De lá Competence - Essaisurun Atrracteur Éntrage. Les Éditions D'Organisations, Quatrième Tirage.

Man, T. W., \& Lau, T. (2000). Entrepreneurial Competecies of Small Business Owner/Managers in the Hong Kong Services Sector: A Qualitative Analysis. Journal of Enterprise Culture, 8(3), 235-254.

Marconi, M. D., \& Lakatos, E. M. (2003). Fundamentos da Metodologia Científica. $5^{\mathrm{a}}$ edição, São Paulo: Atlas.

Martins, S. N. (2010). Educação Empreendedora Transformando o Ensino Superiror: diversos Olhares de Estudantes sobre Professores Empreendedores. Potifícia Universidade Católica do Rio Grande do Sul, Porto Alegre.

McAdam, R., Miler, K., McAdam, M., \& Teague, S. (2012). The Development of University Technology Transfer Stakeholder Relationships at a Regional Level: Lessons for the Future. Technobation, 57-67.

McClelland, D. C. (1961). The Achieving Society. Princenton: D. Van Nostrand Company Inc.

McClelland, D. C. (1973). Testing for Competence Rather Than for "Intelligence". American Psychologist, 14.

McClelland, D. C. (1987). Characteristics of Successful Entrepreneus. The Journal of Creative Behavior, 21(3), 219-233.

MDIC. (2012). Proposta de Teses e Diretrizes para Política Nacional de Empreendedorísmo e Negócios: Consulta Pública. Ministério do Desenvolvimento, Indústria e Comércio Exterior, Brasília. 
MEC. (2013). Ministério da Educação. Acesso em: 23 de novembro de 2019. Disponível em: http://portal.mec.gov.br/ultimas-noticias/209-564834057/18739-ministeriolanca-programa-para-incentivar-o-empreendedorismo

MEC. (2019). Ministério da Educação. Acesso em: 13 de abril de 2019. Disponível em: http://portal.mec.gov.br/institucional

Medeiros, T. C. (2012). Empreendedorismo e Inovação: Um Estudo de Caso Múltiplo na Indústria de Software do Rio Grande do Norte. Universidade Federal do Rio Grande do Sul, Porto Alegre/RS.

Nunes, S. C., \& Barbosa, A. C. (2009). Formação Baseada em Competências? Um Estudo em Cursos de Graduação em Administração. Revista de Administração Mackenzie, 10(5), 28-52.

Oliveira, A. G., Melo, M. C., \& Muylder, C. F. (2016). Educação Empreendedora: Desenvolvimento do Empreendedorismo e Inovação Social em Instituições de Ensino Superior. Revista Administração em Diálogo, 18(1), 29-56.

Parry, S. B. (1996). The Quest for Competencies. Training, 48-54.

PDI-UFGD, P. D. (2013). Plano de Desenvolvimento Institucional-PDI-2013-2017. Universidade Federal da Grande Dourados, Dourados.

Pereira, S. M. (2001). A Formação do Empreendedor. Universidade Federal de Santa Catarina, Florianópolis. Artmed.

Perrenoud, P. (2000). Construir as Competências desde a Escola. Porto Alegre:

Perrenoud, P., Thuler, M. G., Macedo, L. D., Machado, N. J., \& Allessandrini, C. D. (2002). As Competências para Ensinar no Século XXI: A Formação dos Professores e o Desafio da Avaliação. Porto Alegre: Artmed.

Plonski, G. A., \& Carrer, C. D. (2019). A Inovação Tecnológica e a Educação para o Empreendedorismo. EDUSP, 107-135.

Prodanov, C. C., \& Freitas, E. C. (2013). Metodologia do Trabalho Científico: Método e Técnicas da Pesquisa e do Trabalho Acadêmico. $2^{\text {a }}$ edição, Novo Hamburgo: Feevale.

Ramos, M. N. (2006). A Pedagogia das Competências: Autonomia ou Adaptação. $3^{\mathrm{a}}$ edição, São Paulo: Vortez.

Salomão, M. P. (2014). Spin-off da Ciência: Terras Raras do Empreendedorismo Acadêmico Brasileiro?Escola Politécnica da Universidade de São Paulo, São Paulo/SP.

Santos, B. L.(2017). Universidade Empreendedora: Proposta para o Desenvolvimento do Empreendedorismo Acadêmico na Universidade Federal de Santa Catarina. Universidade Federal de Santa Catarina, Florianópolis/SC.

Santos, E. F., \& Benneworth, P. (2019). Interação Universidade-Empresa: Características Identificadas na Literatura e a Colaboração Regional da Universidade de Twente. Revista de Administração, Sociedade e Inovação, 5(2), 115-143. 
Santos, L. S., \& Alvarenga, G. I. (2019). A Lógica Contemporânea das Relações de Trabalho e o Discurso Proferido por uma Empresa de Cosméticos Brasileira: Legitimando uma Ideologia. Revista de Administração, Sociedade e Inovação, 6-20.

Schumpeter, J. A. (1934). The Theory of Economic Development (An Inquiry into Profits, Capital, Credit, Interest and the Business Cycle).Cambridge, São Paulo: Harvard University Department of Economics.

Sebrae. (2017). Empreendedorismo e o Mercado de Trabalho. SEBRAE, Brasília.

Sebrae. (2018). Serviço Brasileiro de Apoio às Micro e Pequenas Empresas. Acesso em: 13 de novembro de 2018. Disponível em: https://eadlms.sebrae.com.br/main/novosebrae/training/classroom/class/25413?topic $=35412$

Serra, B., Serra, F. R., Ferreira, M. P., \&Fiates, G. G. (2011). Fatores Fundamentais para o Desempenho de Incubadoras de Base Tecnológica. Revista de Administração e Inovação, 8(1), 221-247.

Silva, L. C., Kovaleski, J. L., \& Gaia, S. (2013). Gestão do Conhecimento Organizacional visando à Transferência de Tecnologia: Os Desafios enfrentados pelo NIT da Universidade Estadual de Santa Cruz. Revista Científica Eletrônica de Engenharia de Produção, 13(2), 677-702.

Silva, L. C., Kovaleski, J. L., Gaia, S., Segundo, G. S., \& Caten, C. S. (2015). Processo de Transferência de Tecnologia em Universidades Públicas Brasileiras por Intermédio dos Núcleos de Inovação Tecnológica. Interciencia, 40(10), 664-449.

Siqueira, L., \& Nunes, S. C. (2011). Um Olhar sobre o Projéto Pedagógico e as Práticas Docentes baseados na Proposta de Formação por Competências. Administração: Ensino e Pesquisa, 12(3), 415-445.

UFGD, U. F. (2013). Plano de Desenvolvimento Institucional. Universidade Federal da Grande Dourados, Dourados.

UFGD, U. F. (2013). Regulamento da Propriedade Intelectual, Inovação $e$ Transferência de Tecnologia. Universidade Federal da Grande Dourados, Dourados.

UFGD, U. F. (2017). Regimento Interno da Incubadora Empresarial e Tecnológica (GDTec) da Universidade Federal da Grande Dourados. Universidade Federal da Grande Dourados, Dourados.

UFGD, U. F. (2018). Universidade Federal da Grande Dourados. Acesso em: 6 de setembro de 2018. Disponível em: https://www.ufgd.edu.br/setor/nipi/ofertas-patentes

UFGD, U. F. (2018). Universidade Federal da Grande Dourados. Acesso em: 23 de outubro de 2018. Disponível em Universidade Federal da Grande Dourados: https://portal.ufgd.edu.br/

UFGD, U. F. (2019). Divisão das Incubadoras. Acesso em: 28 de abril de 2019. Disponível em: https://portal.ufgd.edu.br/secao/incubadoras-proex/index

UFGD, U. F. (2020). Projeto Pedagógico dos Cursos de Graduação. Fonte: PPCs: https://portal.ufgd.edu.br/coordenadoria/cograd/ppcs

Vedovello, C., \& Figueiredo, P. N. (2005). Incubadora de Inovação: Que Nova Espécie é esta? RAE Eletronica, 4(10). 


\section{Bookman.}

Yin, R. K. (2015). Estudo de Caso: Planejamento e Métodos. $5^{\text {a }}$ edição, Porto Alegre:

Zanchet, R. E. R. (2019). O Ensino do Empreendedorismo nos Cursos de Graduação da Universidade Federal da Grande Dourados: Um Estudo de Caso. Dourados. Universidade Federal da Grande Dourados, UFGD, 212 p.

Zarifian, P. (1999). Objecrif Compétence. Pour une Nouvelle Logique. Laboratoire de Recherche Innovation-Formation-Éducation (Liaisons). 